22. Рябкова К.А. Лишайники Урала: учеб. пособие. Свердловск: Изд-во СГПУ, 1981. 52 с.

23. Флора лишайников России: Биология, экология, разнообразие, распространение и методы изучения лишайников / отв. ред. М.П. Андреев, Д.Е. Гимельбрант. М.; СПб.: Т-во науч. изданий КМК, 2014. 392 c.

24. Макрый Т.В. Лишайники Байкальского хребта. Новосибирск: Наука. Сиб. отделение, 1990. 200 с.
25. Маевский П.Ф. Флора средней полосы европейской части России. 11-е изд. М.: Товарищество научных изданий КМК, 2014. 640 с.

26. Песенко Ю.А. Принципы и методы количественного анализа в фаунистических исследованиях. М.: Наука, 1982. 282 с.

27. Корчиков Е.С. Лишайники Самарской Луки и Красносамарского лесного массива. Самара: Издательство «Самарский университет», 2011. 320 с.

\title{
ECOLOGICAL AND SUBSTRATE CHARACTERISTICS OF LICHENOFLORA OF THE STATE NATURE RESERVE «ZAVOLZHSKY» (CHUVASH REPUBLIC)
}

(C) 2019

\author{
Sinichkin Evgeny Arkadyevich, researcher \\ Dimitriev Aleksandr Veniaminovich, candidate of biological sciences, director \\ Cheboksary Branch of the Main Botanical Garden named after N.V. Tsitsin of the Russian Academy of Sciences \\ (Cheboksary, Russian Federation)
}

Abstract. The paper provides an ecological and substrate analysis of lichens of the State Nature Reserve «Zavolzhsky» (Chuvash Republic). In the specified reserve 134 species of lichens were found. The ecological and substrate analysis showed that lichens were found on 20 substrates: on the bark of Populus tremula, Tilia cordata, Quercus robur, Acer platanoides, Betula pubescens, Padus avium, Sorbus aucuparia, Frangula alnus, Salix cinerea, S. pentandra, Alnus glutinosa, on the bark and branches of Pinus sylvestris, Picea abies, Abies sibirica, Betula pendula, on soil, on a dead organic substrate, on an anthropogenic substrate (on slate, concrete, wheel rubber). 6 main and 4 intermediate ecological groups of lichens were revealed: 1) epiphytic, growing on the bark of trees and shrubs; 2) epixylic, living on decaying wood; 3) epigeidic (ground lichens); 4) epibriophytic, living on mosses; 5) epiphytic-epixylic, growing on the bark of trees and a dead organic substrate; 6) epixylic-epigeidic, living on a dead organic substrate and soil; 7) lichens growing on the bark of trees and anthropogenic substrate; 8) epiphytic-epigeidic, growing on tree bark and soil surface 9) multisubstrate lichens that live on different substrates; 10) lichens of anthropogenic substrate. The largest number of lichens $(61,2 \%)$ belong to epiphytic, $16,5 \%$ - to epiphytic-epixylic, $5,2 \%$ - to epixylic-epigeidic, $4,5 \%$ - to epigeidic, $3,7 \%$ - to epixylic, $2,3 \%$ - to epibriophytic, $0,7 \%$ - to multisubstrate lichens, $0,7 \%$ - to epiphytic-epigeidic. 3 species of lichens were found $(2,3 \%)$ on the anthropogenic substrate. Epiphytic lichens were found on 15 forophytes. The largest number of taxa (40 species) were found on Pinus sylvestris's bark, 35 species - on Populus tremula's bark, 33 species - on Betula pendula's bark. 56 species of lichens were found on only one forophyte. The analysis of the confinement to phorophyte showed that the highest level of similarity in the species composition of lichens was found between Padus avium and Frangula alnus - 50\%, Pinus sylvestris and Picea abies - 49\%, Populus tremula and Sorbus aucuparia - 44\%, Tilia cordata and Acer platanoides - 41\%, Salix cinerea and S. pentandra - 37\%.

Keywords: lichen; state nature reserve «Zavolzhsky»; specially protected natural area; ecological and substrate analysis; ecological groups; substrate confinement; phorophytes; lichen similarity level; Chuvash Zavolzhye; Chuvash Republic.

\section{ЭКОЛОГИЧЕСКИЕ ОСОБЕННОСТИ НЕКОТОРЫХ ВИДОВ СЕМЕЙСТВА ЛАНДЫШЕВЫЕ (CONVALLARIACEAE) В УСЛОВИЯХ КИРОВСКОЙ ОБЛАСТИ}

(C) 2019

Сулейманова Венера Нуритдиновна, кандидат биологических наук, старший научный сотрудник отдела экологии и ресурсоведения растений; доцент кафедры экологии и зоологии

Егошина Татьяна Леонидовна, доктор биологических наук, профессор,

заведующий отделом экологии и ресурсоведения растений; профессор кафедры экологии и зоологии

Всероссийский научно-исследовательский институт охотничьего хозяйства и звероводства им. Б.М. Житкова (г. Киров, Российская Федерация);

Вятская государственная сельскохозяйственная академия (г. Киров, Российская Федерация)

Аннотащия. В связи с антропогенной нагрузкой на естественные местопроизрастания многих лекарственных видов растений актуальным является оценка экологических условий произрастания для изучения взаимоотношений видов и растительных сообществ. В работе представлены результаты анализа экологических условий местообитаний некоторых видов семейства Ландышевые (Convallariaceae) в Кировской области. Для выявления эколого-фитоценотической приуроченности изучаемых видов в лесных сообществах Кировской области исследовано 45 ценопопуляций (ЦП) Convallaria majalis, 10 ЦП Polygonatum odoratum и 20 ЦП Majanthemum bifolium. При анализе экологических условий местообитаний видов использовали экологические шкалы X. Элленберга. Геоботанические описания растительных сообществ проводили согласно общепринятым методам. Установлено, что амплитуды экологических пространств изученных видов в Кировской обла- 
сти практически по всем позициям не укладываются в большинство диапазонов экологических ниш, рассчитанных по шкалам Элленберга. Виды имеют широкий диапазон приспособленности к изученным экологическим факторам. Все исследованные виды распространены на средне-влажных почвах (5-я ступень шкалы Элленберга). Показано, что изучаемые виды схожи по таким экологическим факторам, как влажность и богатство почвы азотом. По отношению к освещенности исследуемые виды различаются Convallaria majalis и Polygonatum odoratum - светолюбивые виды, Majanthemum bifolium - теневыносливый вид. В травяно-кустарничковом ярусе исследуемых местообитаний видов выявлены 7 редких, малочисленных, узкоареальных видов, включенных в Красную книгу Кировской области (Pulsatilia flavescens (Zuccar.) Juz., Potentilla humifusa Willd. ex Schlecht., Centaurea sumensis Kalen., Koeleria glauca (Spreng.) DC., Eryngium planum L., Geranium sanguineum L., Carex bohemica Schreb.), и 4 вида, нуждающихся на территории области в постоянном контроле и наблюдении (Приложение 2), - Campanula perscifolia L., Pulsatilia patens (L.) Mill., Platanthera bifolia (L.) Rich., Iris sibirica L.

Ключевые слова: Polygonatum odoratum (Mill.) Druce; Convallaria majalis L.; Maianthemum bifolium (L.) F.W. Schmidt; Convallariaceae; Кировская область; экологические шкалы; шкалы Элленберга; экологические условия; освещенность; влажность почвы; реакция почвы; обеспеченность почвы азотом; редкие виды; ценопопуляция; эколого-фитоценотическая характеристика; бореальные виды.

\section{Введение}

В связи с антропогенной нагрузкой на естественные местопроизрастания многих лекарственных видов растений актуальным является оценка экологических условий произрастания для изучения взаимоотношений видов и растительных сообществ. Одним из приоритетных направлений в последние годы является выявление эколого-ценотических показателей видов. Экологические шкалы помогают обозначить позиции видов в растительных сообществах и рассчитать количественные характеристики климатических и эдафических факторов.

На территории Кировской области начата работа по изучению видов семейства Ландышевые (Convallariaceae) с выявлением эколого-фитоценотической приуроченности и экологических оптимумов [1-5].

Наиболее известными представителями сем. Ландышевые в Кировской области являются ландыш майский (Convallaria majalis L.), купена душистая или лекарственная (Polygonatum odoratum (Mill.) Druce (P. officinale All.)) и майник двулистный (Majanthemum bifolium (L.) F.W. Schmidt).

Цель работь: выявление экологических особенностей и условий местопроизрастаний видов сем. Ландышевые в Кировской области.

\section{Объекты и методы исследования}

Территория Кировской области располагается в пределах южной и средней тайги и в подтаежной полосе хвойно-широколиственных лесов [6;7].

Флора Кировской области относится к голарктическому царству, бореальному подцарству, циркумполярной области, североевропейской провинции. Современная флора области представлена 1470 видами из 124 семейств [8]. Наиболее крупные по числу видов семейства астровые (Asteraceae) - 169 видов, мятликовые (Poaceae) - 134 вида, розовые (Rosaceae) - 108 видов, осоковые (Суреraceae) - 77 видов, бобовые (Fabaceae) - 63 вида, гвоздичные (Caryophyllaceае) -57 видов.

Объектами исследования являются некоторые представители семейства Ландышевые (Convallariaceae) - ландыш майский (Convallaria majalis L.), майник двулистный (Maianthemum bifolium (L.) F.W. Schmidt.) и купена лекарственная (Polygonatum odoratum (Mill.) Druce).

Для выявления эколого-фитоценотической приуроченности изучаемых видов в лесных сообществах Кировской области исследовано 45 ценопопуляций (ЦП) C. majalis, 10 ЦП P. odoratum и 20 ЦП M. bifolium.
Геоботанические описания растительных сообществ проводили согласно общепринятым методам $[9 ; 10]$.

Для анализа экологических условий местообитаний видов выбраны экологические шкалы Х. Элленберга [11].

Названия растений приведены по С.К. Черепанову [12].

При отборе почвенных образцов и анализе почвенных проб на содержание органического углерода (\%) и кислотности использовали методику Е.В. Аринушкиной [13].

\section{Результаты исследований и их обсуждение}

Все изученные виды являются автохорами, летнезелеными поликарпиками, геофитами, мезофиллами [14-18], имеют лекарственное, декоративное, ядовитое, медоносное значения [19-21].

Maianthemum bifolium - циркумбореальный, бореальный вид. В Кировской области M. bifolium встречается в еловых, сосновых, реже смешанных и лиственных лесах.

Polygonatum odoratum - евразиатский, неморальный вид, в области произрастает в сосновых, реже еловых, смешанных и лиственных лесах, зарослях кустарников.

Convallaria majalis - циркумбореальный, бореально-неморальный вид. В районе исследований отмечен в основном в сосновых и лиственных лесах области. Вид включен в Приложение 2 Красной книги Кировской области [22]. В области в пределах подзоны хвойно-широколиственных лесов проходит северо-восточная граница ценоареала C. majalis. Отдельные местообитания вида выявлены в подзоне южной тайги в Котельническом, Слободском районах и окрестностях г. Кирова [23].

Краткая эколого-фитоценотическая характеристика исследуемых видов дана в таблице 1 .

В травяно-кустарничковом ярусе исследуемых местообитаний видов выявлены редкие, малочисленные, узкоареальные виды, включенные в Красную книгу Кировской области с категорией редкости III прострел желтеющий (Pulsatilia flavescens (Zuccar.) Juz.), лапчатка распростертая (Potentilla humifusa Willd. ex Schlecht.), василек сумской (Centaurea sumensis Kalen.), тонконог сизый (Koeleria glauca (Spreng.) DC.), синеголовник плосколистный (Eryngium planum L.), герань кроваво-красная (Geranium sanguineum L.). Кроме того, встречается редкий вид, численность которого быстро сокращается (II), - осока богемская (Carex bohemica Schreb.). 
Таблица 1 - Эколого-фитоценотическая характеристика исследуемых видов

\begin{tabular}{|c|c|c|c|c|}
\hline \multirow[b]{2}{*}{$\begin{array}{c}\text { Изучаемые } \\
\text { виды }\end{array}$} & \multicolumn{3}{|c|}{ Таксационные параметры древесного яруса } & \multirow[b]{2}{*}{ Редкие виды } \\
\hline & $\begin{array}{l}\text { Средний возраст } \\
\text { древостоя, лет }\end{array}$ & $\begin{array}{c}\text { Сомкнутость } \\
\text { древостоя }\end{array}$ & $\begin{array}{c}\text { Средняя высота } \\
\text { древостоя, м }\end{array}$ & \\
\hline $\begin{array}{l}\text { Maiantheтит } \\
\text { bifolium }\end{array}$ & $50-150$ & $0,3-0,9$ & $20-29$ & Не обнаружены \\
\hline $\begin{array}{l}\text { Polygonatum } \\
\text { odoratum }\end{array}$ & $15-100$ & $0,3-0,6$ & $12-25$ & $\begin{array}{l}\text { Convallaria majalis, Pulsatilia patens (L.) } \\
\text { Mill., Platanthera bifolia (L.) Rich., Potentil- } \\
\text { la humifusa Willd. ex Schlecht., Centaurea } \\
\text { sumensis Kalen., Koeleria glauca (Spreng.) } \\
\text { DC., Pulsatilia flavescens (Zuccar.) Juz. }\end{array}$ \\
\hline $\begin{array}{l}\text { Convallaria } \\
\text { majalis }\end{array}$ & $25-150$ & $0,2-0,9$ & $8-33$ & $\begin{array}{l}\text { Eryngium planum L., Iris sibirica L., Pulsa- } \\
\text { tilia flavescens (Zuccar.) Juz., Platanthera bi- } \\
\text { folia (L.) Rich., Geranium sanguineum L., } \\
\text { Pulsatilia patens (L.) Mill., Carex bohemica } \\
\text { Schreb., Campanula perscifolia } \text { L. }\end{array}$ \\
\hline
\end{tabular}

В составе фитоценозов, включающих исследованные виды, выявлены виды, нуждающиеся на территории области в постоянном контроле и наблюдении (Приложение 2), - колокольчик персиколистный (Campanula perscifolia L.), прострел раскрытый (Pulsatilia patens (L.) Mill.), любка двулистная (Platanthera bifolia (L.) Rich.), ирис сибирский (Iris sibirica L.).

Результаты анализа почв показали, что M. bifolium обитает на кислых почвах, размах варьирования pH от 3 до 4, у C. majalis и P. odoratum пределы варьирования $\mathrm{pH}$ от 3 до 7 (рис. 1). Определение органического углерода показало, что его содержание в сообществах с исследуемыми видами колеблется: от 0,83 до $9,66 \%$ у M. bifolium, от 0,51 до $11,5 \%$ у C. majalis и от 0,82 до $12,3 \%$ у P. odoratum.

Сравнительный анализ экологических шкал местообитаний изучаемых видов показал следующее.

Амплитуды экологических пространств изученных ЦП в Кировской области практически по всем шкалам выходят за пределы диапазонов экологического ареала по шкалам Элленберга.

Значения шкалы кислотности почв у ЦП P. odoratum расположены близко к значениям кислотности шкалы Элленберга (рис. 2: A), у C. majalis - значения шкалы богатство почв азотом (рис. 2: Б), у M. bifoli$u m$ - значения шкалы влажности почв (рис. 2: $B$ ). Исследованные виды распространены на средне-влажных почвах (5-я ступень шкалы Элленберга).

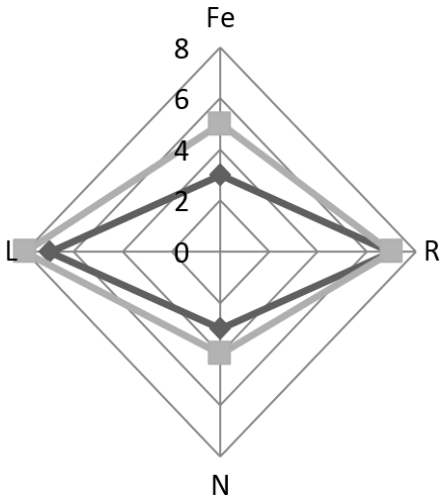

A

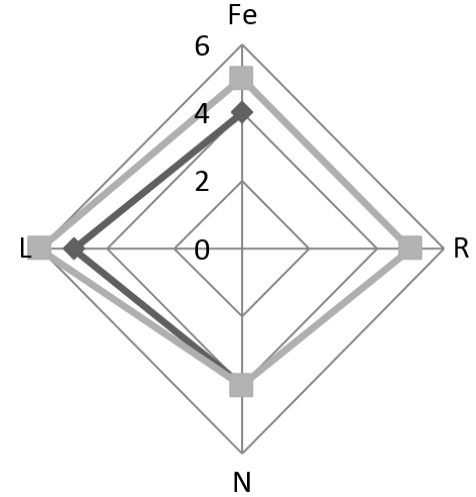

Б

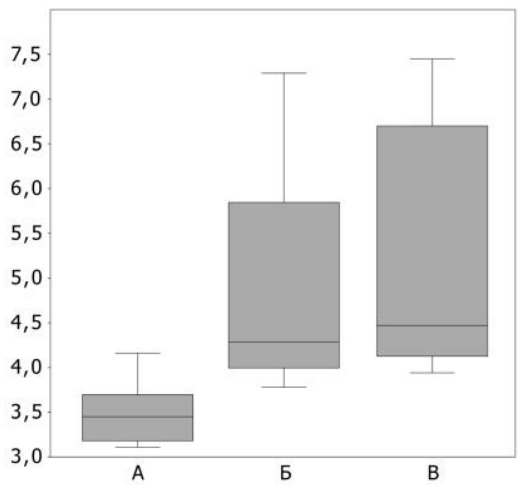

Рисунок 1 - Средние значения кислотности (рН; по оси ординат) почвы

в сообществах изучаемых видов.

Условные обозначения: $A$ - Maianthemum bifolium 5 - Convallaria majalis, $B$ - Polygonatum odoratum

По шкале освещенности изучаемые сообщества M. bifolium отмечены в условиях от полутени до тени (5-я ступень шкалы Элленберга), вид характеризуется как теневыносливый. C. majalis является теневыносливым и светолюбивым видом, встречаясь в местопроизрастаниях от полутени до полного освещения (6-я ступень шкалы Элленберга). P. odoratum светолюбивое растение, может расти при полной освещенности с количеством света до 40\% (8-я ступень шкалы Элленберга).

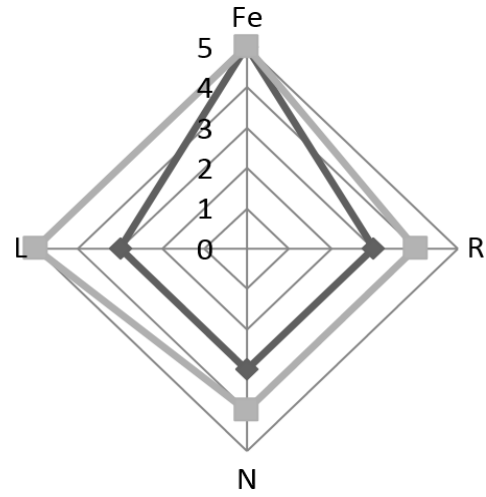

B

Рисунок 2 - Характеристика местообитаний изучаемых видов, баллы (по экологическим шкалам Элленберга). Условные обозначения: $A$ - Polygonatum odoratum, 5 - Convallaria majalis, B - Maianthemum bifolium. $L$ - освещенность, $F e$ - влажность почвы, $R$ - реакция почвы, $N$ - обеспеченность почвы азотом.

Светло-серым цветом обозначен диапазон экологического пространства исследованных цП; темно-серым цветом - диапазон экологического ареала по шкалам Элленберга 


\section{Выводы}

Исследования показали, что амплитуды экологических пространств изученных ЦП в Кировской области практически по всем шкалам выходят за пределы диапазонов экологического ареала по шкалам Элленберга. Балльные значения широко варьируют. Изучаемые виды схожи по таким экологическим факторам, как влажность и богатство почвы азотом. По отношению к освещенности исследуемые виды различаются. C. majalis и P. odoratum - светолюбивые виды, $M$. bifolium - теневыносливый вид.

В травяно-кустарничковом ярусе зарегистрированы 7 редких, малочисленных видов, включенных в Красную книгу Кировской области, и 4 вида, нуждающихся на территории области в постоянном контроле и наблюдении (Приложение 2).

\section{Список литературы:}

1. Сулейманова В.Н., Ишмуратова М.М., Ишбирдин А.Р. Экологические характеристики и стратегии жизни Maianthemum bifolium (L.) F.W. Schmidt в леcax Европейского сектора подзоны южной тайги // Вестник БашГУ. 2007. № 4 (12). С. 41-42.

2. Сулейманова В.Н., Ишмуратова М.М., Егошина Т.Л. Состояние ценопопуляций Maianthemum bifolium (L.) F.W. Schmidt (Liliaceae) в южно-таежной подзоне Кировской области // Раст. ресурсы. 2012. Т. 48, вып. 4. С. 504-517.

3. Сулейманова В.Н. Особенности плодоношения и демографические характеристики ценопопуляций Maianthemum bifolium (L.) F.W. Schmidt в таежной и подтаежной зоне // Вестник СамГУ. Естественнонаучная серия. 2006. № 7 (47). С. 212-216.

4. Сулейманова В.Н., Егошина Т.Л. Эколого-фитоценотическая характеристика Convallaria majalis L. в подзоне хвойно-широколиственных лесов Кировской области // Вестник Удмуртского государственного университета. 2014. Вып. 1. С. 49-56.

5. Егорова Н.Ю., Сулейманова В.Н., Егошина Т.Л. Экологические предпочтения некоторых доминантов травяно-кустарничкового яруса таежных фитоценозов // Сохранение лесных экосистем: проблемы и пути их решения: мат-лы всерос. науч.-практ. конф. (г. Киров, 15-19 мая 2017 г.). Киров: ООО «Издательство «Радуга-ПРЕСС», 2017. С. 218-221.

6. Геоботаническое районирование Нечерноземья европейской части РСФСР. Л.: Наука, 1989. 64 с.

7. Леса Кировской области / под ред. А.И. Видякина, Т.Я. Ашихминой, С.Д. Новоселова. Киров: Кировская областная типография, 2007. 400 с.
8. Тарасова Е.М. Флора Вятского края. Ч. 1. Сосудистые растения. Киров: Кировская областная типография, 2007. 440 с.

9. Методы изучения лесных сообществ: монография / Е.Н. Андрева, И.Ю. Баккал, В.В. Горшков и др. СПб.: НИИХ Химии СПбГУ, 2002. 240 с.

10. Миркин Б.М., Наумова Л.Г. Наука о растительности: История и соврем. состояние основных концепций. Уфа: Гилем, 1998. 412 с.

11. Ellenberg H. Zeigerwerte der Gefaspflanzen Mitteleuropas. Gottingen, 1974. $97 \mathrm{s.}$

12. Черепанов С.Н. Сосудистые растения России и сопредельных государств. СПб.: Мир и семья, 1995. 990 c.

13. Аринушкина Е.В. Руководство по химическому анализу почв. М.: Изд-во МГУ, 1970. 487 с.

14. Крылова И.Л. О фитоценотическом оптимуме и его критериях // Популяционная экология растений: мат-лы конф. М.: Наука, 1987. С. 14-18.

15. Крылова И.Л. Convallaria majalis L. как компонент растительных сообществ // Растительные ресурсы. 1993. Т. 29, вып. 2. С. 1-10.

16. Вахрамеева М.Г., Малева Н.В. Майник двулистный // Биологическая флора Московской области. Т. 8. М.: Изд-во МГУ, 1990. С. 91-101.

17. Рысина Г.П. Ранние этапы онтогенеза лесных травянистых растений Подмосковья. М.: Наука, 1973. C. $16-17$.

18. Полянская Т.А., Леонтьева И.И., Шестакова Э.В., Файзуллина С.Я. Онтогенез майника двулистного (Maianthemum bifolium (L.) F.W. Schmidt.) // Онтогенетический атлас лекарственных растений. Т. 2 / под ред. Л.А. Жуковой. Йошкар-Ола: МарГУ, 2000. С. 210-215.

19. Дикорастущие полезные растения России / отв. ред. А.Л. Буданцев, Е.Е. Лесиовская. СПб.: Издательство СПХФА, 2001. С. 213-216.

20. Государственная фармакопея Российской Федерации. ХІІІ изд., т. III. М., 2015. 1294 с.

21. Машковский М.Д. Лекарственные средства. 16-е изд. М.: Волна, 2017. 1216 с.

22. Красная книга Кировской области: Животные, растения, грибы. 2-е изд. / под ред. О.Г. Барановой, Е.П. Лачохи, В.М. Рябова, В.Н. Сотникова, Е.М. Тарасовой, Л.Г. Целищевой. Киров: Кировская областная типография, 2014. 336 с.

23. Егорова Н.Ю., Сулейманова В.Н., Егошина Т.Л. Растительный покров особо охраняемых природных территорий поймы реки Вятка // Самарский научный вестник. 2018. Т. 7, № 2 (23). С. 31-36.

\section{ECOLOGICAL FEATURES OF SOME SPECIES OF THE LILY OF THE VALLEY FAMILY (CONVALLARIACEAE) IN THE KIROV REGION} (C) 2019

Suleimanova Venera Nuritdinovna, candidate of biological sciences, senior researcher of Ecology and Plant Resources Department; associate professor of Ecology and Zoology Department

Egoshina Tatyana Leonidovna, doctor of biological sciences, professor,

head of Ecology and Plant Resources Department; professor of Ecology and Zoology Department Professor Zhitkov Russian Research Institute of Game Management and Fur Farming (Kirov, Russian Federation); Vyatka State Agricultural Academy (Kirov, Russian Federation)

Abstract. In connection with the anthropogenic load on the natural habitats of many medicinal plant species, it is relevant to assess the ecological conditions of growth in order to study the relationships between species and plant communities. The paper presents the analysis of ecological features of some species of the Lily of the valley family (Convallariaceae) in the Kirov Region. To identify the ecological-phytocoenotic association of the studied species in 
forest communities of the Kirov Region, 45 coenotic populations (CP) of Convallaria majalis, $10 \mathrm{CP}$ of Polygonatum odoratum and $20 \mathrm{CP}$ of Majanthemum bifolium were studied. When analyzing the ecological conditions of the species habitats, H. Ellenberg ecological scales were used. Geobotanical descriptions of plant communities were carried out according to generally accepted methods. It has been established that the amplitudes of the ecological spaces of the studied species in the Kirov Region practically do not fit into most ranges of ecological niches calculated on the basis of $\mathrm{H}$. Ellenberg scales. The species have a wide range of adaptability to the studied environmental factors. All studied species are distributed on medium-moist soils $\left(5^{\text {th }}\right.$ level of $\mathrm{H}$. Ellenberg scale). The authors have shown that the studied species are similar in environmental factors such as moisture and soil richness with nitrogen. Convallaria majalis and Polygonatum odoratum - photophilous species, Majanthemum bifolium - shade-tolerant species are distinguished with respect to illumination. In the grass-shrub layer of the studied habitats of the species, 7 rare, small, narrowly araic species are listed in the Red Book of the Kirov Region (Pulsatilia flavescens (Zuccar.) Juz., Potentilla humifusa Willd. ex Schlecht., Centaurea sumensis Kalen., Koeleria glauca (Spreng.) DC., Eryngium planum L., Geranium sanguineum L., Carex bohemica Schreb.). And 4 species that need constant monitoring and observation in the region (Annex 2) - Campanula perscifolia L., Pulsatilia patens (L.) Mill., Platanthera bifolia (L.) Rich., Iris sibirica L.).

Keywords: Polygonatum odoratum (Mill.) Druce; Convallaria majalis L.; Maianthemum bifolium (L.) F.W. Schmidt; Convallariaceae; Kirov Region; ecological scales; H. Ellenberg scales; environmental conditions; illumination; soil moisture; soil reaction; nitrogen supply to soil; rare species; coenotic population; ecologicalphytocoenotic characterization; boreal species.

$* * *$

УДК 574.3:581.5

DOI 10.24411/2309-4370-2019-14116

Статья поступила в редакцию 06.10.2019

\section{ИСПОЛЬЗОВАНИЕ МОРФОМЕТРИЧЕСКИХ И ФЕНОЛОГИЧЕСКИХ ПОКАЗАТЕЛЕЙ TILIA CORDATA MILL. ДЛЯ ЦЕЛЕЙ БИОИНДИКАЦИИ}

(C) 2019

Турмухаметова Нина Валерьевна, кандидат биологических наук, доцент кафедры биологии Марийский государственный университет (2. Йошкар-Ола, Российская Федераиия)

Аннотация. Приведены результаты многолетних биоиндикационных исследований оценки состояния липы сердцевидной (Tilia cordata Mill.) в условиях г. Йошкар-Олы, различающихся степенью загрязнения среды промышленно-транспортными выбросами. В работе проанализирована изменчивость особей Tilia cordata различных онтогенетических состояний генеративного периода по комплексу морфологических и фенологических признаков с помощью статистических методов главных компонент и дисперсионного анализа. Установлена неоднородность онтогенетических групп деревьев по морфологическим и фенологическим признакам. У средневозрастных генеративных особей мезобионтного вида T. cordata в условиях средней степени загрязнения городской среды отмечается мелколистность. С увеличением антропогенной нагрузки уменьшается площадь листовой пластинки, однако возрастает площадь ее повреждения. Показатель флуктуирующей асимметрии листовой пластинки не отличается у деревьев, произрастающих в различных экологических условиях. Использование метода главных компонент позволило выявить наиболее изменчивые признаки побегов и ритмов сезонного развития у T. cordata, которые можно использовать для целей биоиндикации: размеры и число структурных элементов почек и побегов, сроки и длительность фенофаз. Наиболее чувствительными к загрязнению среды обитания являются средневозрастные генеративные деревья T. cordata.

Ключевые слова: Tilia cordata; биоиндикация; качество среды; загрязнение среды; популяция; онтогенетическое состояние; мезобионт; сезонное развитие; фенофаза; годичный прирост побега; листовая пластинка; площадь листа; повреждение листа; флуктуирующая асимметрия; город Йошкар-Ола; Республика Марий Эл.

\section{Введение}

В рамках популяционно-онтогенетического направления [1;2] важной является проблема изучения изменчивости растений на организменном уровне и поиск признаков-маркеров онтогенетических состояний особей. С другой стороны, при изучении изменчивости растений, обитающих в техногенной среде, необходимо выявить признаки, которые являются индикаторами качества среды обитания.

Древесные насаждения являются важным объектом средообразования урбоэкосистем, ценным индикатором состояния окружающей среды [3]. В качестве биоиндикационных признаков исследователи чаще используют разнообразные морфометрические показатели вегетативных и генеративных органов растений, реже - изменения ритмов их сезонного развития [4-7]. В работах популяционно-онтогенети- ческого направления [8; 9] показано, что неоднородность ритмов сезонного развития особей одной ценопопуляции может являться механизмом адаптации к изменяющимся условиям среды. Исследование ритмологической поливариантности онтогенеза растений может способствовать выявлению наиболее чувствительных видов и признаков-маркеров качества среды обитания.

Цель исследования: проанализировать изменчивость особей липы сердцевидной (Tilia cordata Mill.) различного биологического возраста по комплексу морфометрических и фенологических признаков.

\section{Объекты исследования}

T. cordata относится к мезобионтным видам и имеет средние экологические диапазоны по климатическим и почвенным факторам шкал Д.Н. Цыганова $[10 ; 11]$. T. cordata не обладает высокой газо- и 